\title{
Drying and Heating Modelling of Granular Flow: Application to the Mix-Asphalt Processes
}

\author{
L. LeGuen ${ }^{\dagger}$, F. Huchet and P. Tamagny \\ Institut Français des Sciences et Technologies des Transports, de l'Aménagement et des Réseaux, \\ Bouguenais, F CS 44344, France \\ $\dagger$ Corresponding Author Email: lauredan.leguen@ifsttar.fr
}

(Received April 25, 2010; accepted March 13, 2011)

\begin{abstract}
Concrete asphalt is a hydrocarbon material that includes a mix of mineral components along with a bituminous binder. Prior to mixing, its production protocol requires drying and heating the aggregates. Generally performed in a rotary drum, these drying and heating steps within mix asphalt processes have never been studied from a physical perspective. We are thus proposing in the present paper to analyze the drying and heating mechanisms when granular materials and hot gases are involved in a co-current flow. This process step accounts for a large proportion of the overall energy consumed during hot-mix asphalt manufacturing. In the present context, the high energy cost associated with this step has encouraged developing new strategies specifically for the drying process. Applying new asphalt techniques so that an amount of moisture can be preserved in the asphalt concrete appears fundamental to such new strategies. This low-energy asphalt, also referred to as the "warm technique", depends heavily on a relevant prediction of the actual moisture content inside asphalt concrete during the mixing step. The purpose of this paper is to present a physical model dedicated to the evolution in temperature and moisture of granular solids throughout the drying and heating steps carried out inside a rotary drum. An initial experimental campaign to visualize inside a drum at the pilot scale (i.e. 1/3 scale) has been carried out in order to describe the granular flow and establish the necessary physical assumptions for the drying and heating model. Energy and mass balance equations are solved by implementing an adequate heat and mass transfer coupling, yielding a 1D model from several parameters that in turn drives the physical modeling steps. Moreover, model results will be analyzed and compared to several measurements performed in an actual asphalt mix plant at the industrial scale (i.e. full scale).
\end{abstract}

Keywords: Asphalt mix plant, Rotary drum dryer, Granular flow, Heat and mass transfer, Modeling.

\section{NOMENClature}

\begin{tabular}{|c|c|c|c|}
\hline \multirow{3}{*}{$\begin{array}{l}C \\
C p\end{array}$} & Concentration (kg. $\left.\mathrm{m}^{-3}\right)$ & $\mathrm{Nu}$ & Nusselt number \\
\hline & Specific heat capacity at constant & $P$ & Pressure $(\mathrm{Pa})$ \\
\hline & pressure $\left(\mathrm{J} \cdot \mathrm{kg}^{-1} \cdot \mathrm{K}^{-1)}\right.$ & $\operatorname{Pr}$ & Prandtl number \\
\hline$D$ & Diffusion coefficient $\left(\mathrm{m}^{2} . \mathrm{s}^{-1}\right)$ & $T$ & Temperature $(\mathrm{K})$ \\
\hline$d$ & Size of the solid particle (m) & $R$ & Perfect gas constant $\left(\mathrm{J} . \mathrm{mol}^{-1} \cdot \mathrm{K}^{-1}\right)$ \\
\hline$e$ & Wall thickness (m) & $\operatorname{Re}$ & Reynolds number \\
\hline ext & Exterior environment & $S$ & linear exchange area density $\left(\mathrm{m}^{2} \cdot \mathrm{m}^{1}\right)$ \\
\hline $\mathrm{Fr}$ & Froude number & $S c$ & Schmidt number \\
\hline$g$ & Gravitation constant $\left(\mathrm{m} . \mathrm{s}^{-2}\right)$ & $S h$ & Sherwood number \\
\hline$g$ & Gas & $s$ & Solid particle \\
\hline$g e$ & Gas/exterior & satH2O & Saturation of water \\
\hline$g s$ & Gas/solid particle & se & Solid particle/exterior \\
\hline$g s 2$ & Gas/surface of the granular bed & $V$ & Velocity $\left(\mathrm{m} \cdot \mathrm{s}^{-1}\right)$ \\
\hline$h$ & Heat transfer coefficient $\left(\mathrm{W} \cdot \mathrm{m}^{-2} \cdot \mathrm{K}^{-1}\right)$ & Vol & Volume $\left(\mathrm{m}^{3}\right)$ \\
\hline$k$ & Mass transfer coefficient $\left(\mathrm{kg} . \mathrm{s}^{-1}\right)$ & vap & Water vapour \\
\hline$L$ & Width of the granular bed $(\mathrm{m})$ & $X$ & Moisture $(\%)$ \\
\hline$L v$ & Latent heat of vaporization & $\alpha$ & Thermal diffusion coefficient $\left(\mathrm{m}^{2} \cdot \mathrm{s}^{1}\right)$ \\
\hline$M$ & molar mass $\left(\mathrm{kg} \cdot \mathrm{mol}^{-1}\right)$ & $\lambda$ & Thermal conductivity $\left(\mathrm{W} \cdot \mathrm{m}^{-1} \cdot \mathrm{K}^{-1}\right)$ \\
\hline$m$ & Linear mass density $\left(\mathrm{kg} \cdot \mathrm{m}^{-1}\right)$ & $\mu$ & Dynamic viscosity (m.s.kg $\left.{ }^{-1}\right)$ \\
\hline$\dot{m}$ & Linear mass rate of $\mathrm{H}_{2} \mathrm{O}$ vapour & $v$ & matic viscosity $\left(\mathrm{m}^{2} \cdot \mathrm{s}^{-1}\right)$ \\
\hline & $\left(\mathrm{kg} \cdot \mathrm{s}^{-1} \cdot \mathrm{m}^{-1}\right)$ & $\rho$ & Density $\left(\mathrm{kg} \cdot \mathrm{m}^{-3}\right)$ \\
\hline$N$ & Rotation velocity (rpm) & Rot & ion velocity (rad.s-1) \\
\hline
\end{tabular}




\section{INTRODUCTION}

Hot-mix asphalt production offers a significant research challenge in terms of energy consumption and $\mathrm{CO}_{2}$ emissions reduction within the road sector (U.S. Environmental Protection Agency 2004). This process basically consists of mixing stones (mineral aggregate) and bitumen binder to produce the asphalt mix, which is also called "asphalt concrete". However, the aggregates must be dried and heated prior to mixing in order to obtain satisfactory fluidity (handling) of the concrete, hence the origin of the term "hot-mix asphalt". Among a wide array of current drying technologies (e.g. tunnel dryer, furnace, disk dryer, atomization, flash dryer, fluidized bed), the rotary dryer is favored in mix asphalt production for its ability to remove moisture from the aggregates.

Hot asphalt mixing is by far the main process involved in road and pavement construction. A large proportion of the energy consumed is due to the drying and heating of aggregates before coating with the bitumen binder. Recent estimations for example cite up to $3 \mathrm{TWh} /$ year in consumption, which accounts for 800,000 $\mathrm{TeqCO}_{2} /$ year in France. In addition to this permanent challenge of reducing energy consumption (Mujumdar 2007), with respect to the environmental impacts of this process, French concrete asphalt production represents approx. 42 million tons of hot-mix asphalt per year, from roughly 600 asphalt mix plants inventoried.

The rotary drum dryer features a long rotating cylindrical shell slightly inclined to the horizontal. In a direct heat rotary dryer, hot gas is supplied by a burner operating in turbulent flow regime through the dryer. These hot combustion gases in turn provide the heat required for vaporization of the water and heating of the aggregates. At the end of the drying and heating steps, the aggregates are in an appropriate condition to be successfully mixed with bitumen until reaching a temperature of roughly $440^{\circ} \mathrm{K}$.

Recently, new techniques have been developed that involve a drop in aggregate temperature. This lowtemperature technique is also referred to as "warm asphalt" (i.e. at temperatures above $373^{\circ}-383^{\circ}$ Kelvin); included herein is the LEA technique (Romier 2006) or "half-warm asphalt" (between $313^{\circ}$ and $373^{\circ} \mathrm{K}$ ), which is currently being marketed and considered as a new sustainable process in terms of energy cost savings and greenhouse gas reduction (Krisjantdottr 2007). The warm asphalt technique requires only limited water content inside the aggregates prior to mixing with bitumen. Knowledge of the actual water content and temperature of aggregates just before mixing is thus of paramount importance in controlling these warm techniques. The rotary drum dryer offers a complete operation that entails thermal drying and heating, depending on particle motion in the dryer. The mixing of solids plays a critical role in the various transfer phenomena (momentum, heat and mass).

Several authors have studied the distribution of granular solids (aggregates) to characterize the different types of granular flow regimes inside rotary baffles during the drying process (Iguaz 2003; Lisboa 2007). These baffles or "flights" are inserted into the rotary drum wall. The most direct form of heat dryers used in the hot-mix asphalt process contains such flights, set in parallel along the length of the shell; the flights serve to lift solids so that they fall across the dryer cross-section as a way of initiating gas-solid contact. The transport of solids through the drum takes place by the action of solids cascading from these flights. Each cascade, comprising the lifting cycle on a given flight design, is essential to stimulating the gas-solid contact required for rapid and homogeneous drying.

Drying inside rotary drum flights is a very recent research topic: either the agitated solids are treated as a purely granular flow in the mix (Huang 2009) or the mass transfer is included within a global model (Sheehan 2005). A few studies carried out with complex processes have focused on the stirred mixing of complex systems with: momentum (Zhu 2004), heat (Chaudhuri 2006; Chen 2008), or mass transfer coupling (Heydenrich 2002). The DEM (Discrete Element Modeling) Bertrand 2005) and CFD (Computational Fluid Dynamics) (Ristow 1998) methods are currently being used as modeling tools for the dispersed and continuous phases, respectively.

This paper presents a drying and heating model capable of predicting the temperature and moisture evolution of aggregates inside a co-current rotary drum. At first, the assumptions relative to granular transport will be derived from results of experiments conducted at a pilot scale (i.e. 1/3). The evolution in granular media distribution within the rotary drum cross-section will be discussed in Section 2. Section 3 will then display the one-dimensional model, based on mass and energy balance, in order to predict evolution in aggregate temperature and moisture along the rotary dryer axis.

As determined by the granular transport regime, each area of exchange between gas flow and granular medium will be evaluated. In addition, each parameter involved in the model will be identified and quantified based on model results. Section 4 will compare these model results to output from an experimental campaign built around temperature measurements and performed inside an instrumented asphalt mixing plant (i.e. fullscale). Several experimental campaigns have been undertaken to provide gas temperature profiles inside the drum during a permanent production run. The model will be validated by means of the measured gas temperature. The production parameters presented in this paper correspond to the given asphalt technique (i.e. hot- and warm-mix asphalt).

\section{GRANULAR TRANSPORT AND PHYSICAL ASSUMPTIONS}

\subsection{Experimental Visualization at the Pilot Scale}

The granular regime in a rotary drum without baffles has been studied on several occasions. Such regimes have been observed and classified by both Henein et al. (1993) and Mellman (2001). 

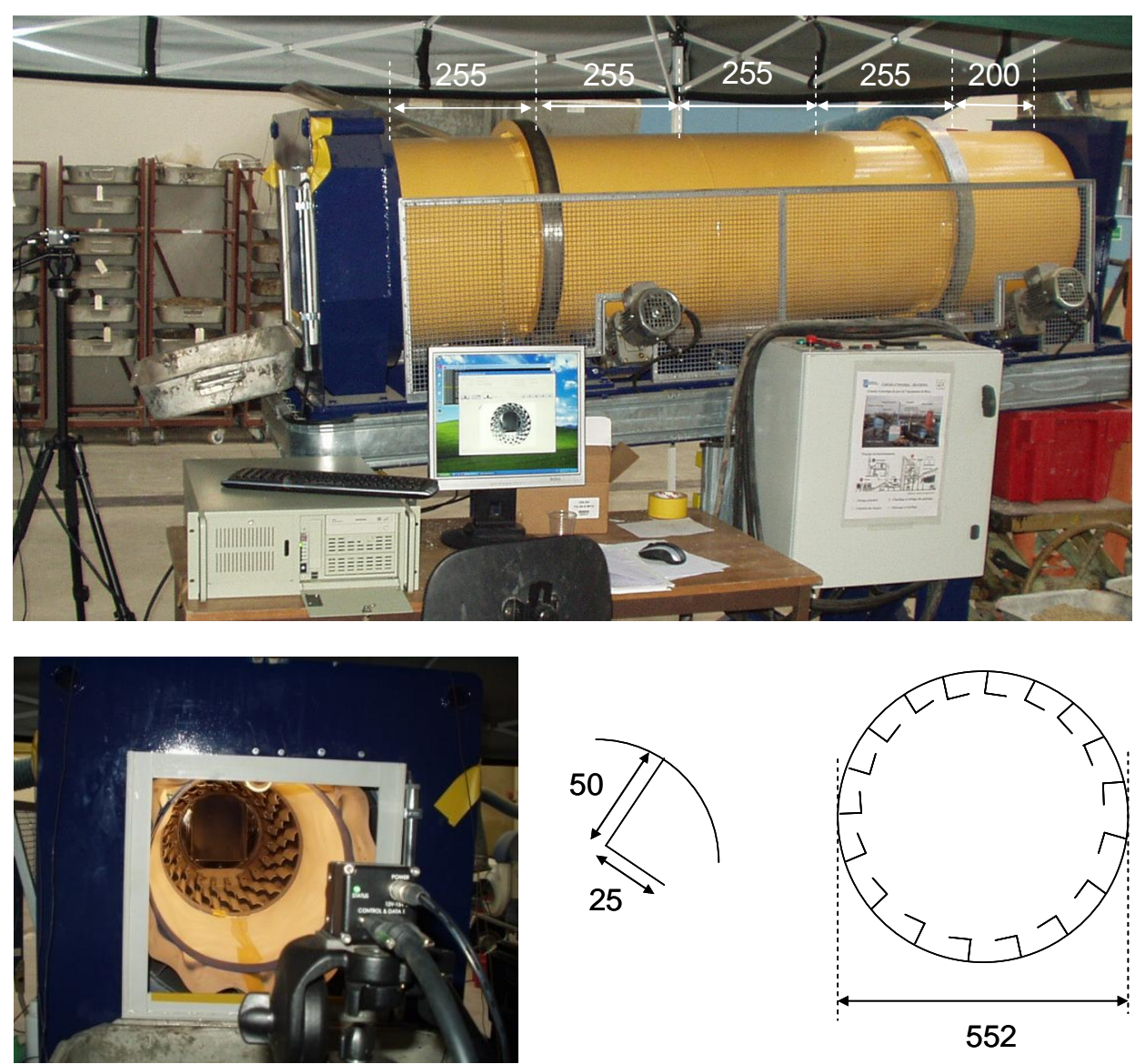

Fig. 1. Description of pilot scale device

The various granular solid motions, including slipping, rolling, avalanching, cataracting and centrifuging, have all been correlated with drum rotation velocity. The granular solid motion is classified mainly by the Froude number $\left(\mathrm{Fr}=\mathrm{R} \omega^{2} / \mathrm{g}\right)$. Table 1 lists the various motions as a function of Froude number. The drum configuration used in the asphalt mixing plant is quite atypical however due to the positioning and shape of the baffles (or flights) along the drum. Experimental campaigns at the pilot scale of an industrial unit have been carried out in order to observe aggregate distribution within the drum cross-section, in the absence of gas flow.

Table 1 Froude number for each of the different modes (Henein 1983)

\begin{tabular}{|l|c|}
\hline \multicolumn{1}{|c|}{ Mode } & $\mathrm{Fr}$ \\
\hline 1. Slipping & $\mathrm{Fr}<1.0 \times 10^{-5}$ \\
\hline 2. Slumping & $1.0 \times 10^{-5}<\mathrm{Fr}<0.3 \times 10^{-3}$ \\
\hline 3. Rolling & $0.5 \times 10^{-3}<\mathrm{Fr}<0.2 \times 10^{-1}$ \\
\hline 4. Cascading & $0.4 \times 10^{-1}<\mathrm{Fr}<0.8 \times 10^{-1}$ \\
\hline 5. Cataracting & $0.9 \times 10^{1}<\mathrm{Fr}<1.0$ \\
\hline 6. Centrifuging & $\mathrm{Fr}>1.0$ \\
\hline
\end{tabular}

The first objective of this visualization step is intended to establish the physical basis of the transfer phenomena taking place inside the drum from knowledge of the granular media in the mix. These flights actually influence the transport of solids, as was mentioned by Huang et al. (2009). The motions recorded in a smooth drum are delayed at lower Froude numbers; moreover, moisture content can influence the granular flow regime and consequently the gas flow distribution. A good knowledge of the granular flow is therefore essential to setting correct assumptions for the heat and mass transfer modeling process.

A time-resolved camera is used to capture instantaneous images; this system features a DALSA FA-20-01M1H camera $(100 \mathrm{~Hz}$, with a resolution of $1400 \times 1024$ pixels). Spherical glass beads are introduced as the seeding particles; their average diameter equals $2 \mathrm{~mm}$ and their density is close to 2.5 . Dry $\left(\mathrm{X}_{\mathrm{s}}=0 \%\right)$ and wet $\left(X_{\mathrm{s}}=8 \%\right)$ aggregates with a mean diameter of $6 \mathrm{~mm}$ have also been tested. A dedicated processor, the STEMMER IMAGING device, serves to acquire data and therefore processes each image.

The 2D experiments have been carried out on a pilotscale device with an inclination angle equal to 3 degrees. The rotary drum diameter $\mathrm{D}=552 \mathrm{~mm}$ (see Fig. 1). The drum is stirred by 20 baffles, each of length $50 \mathrm{~mm}$ and width $25 \mathrm{~mm}$.

The experiments were conducted at a rotational speed of $\mathrm{N}=18 \mathrm{rpm}$. The Froude number thus equals 0.01 , and the granular flow regime corresponds to rolling in a smooth drum. The working area of the drum $(1.22 \mathrm{~m}$ in length) is composed of five sections: one $(200 \mathrm{~mm}$ long) is dedicated to the inlet area for materials, while each of the other four is $255 \mathrm{~mm}$ long. The pilot is not set at the feeding rate; its scale ratio is equal to $1 / 3$, in 
comparison with an industrial drum. Regardless of the materials introduced, the fill rate is fixed at $15 \%$ over the first section of the drum. The frequency of the highspeed camera is adjusted to $25 \mathrm{~Hz}$ in order to strike a compromise between spatial resolution and temporal accuracy.

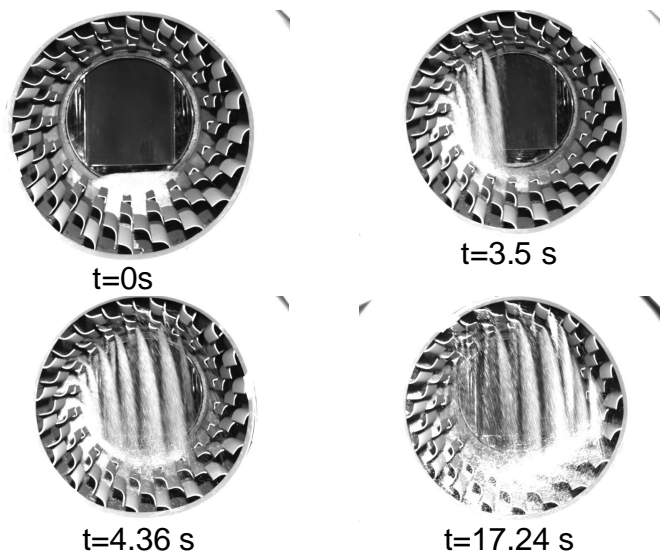

Fig. 2. Transversal motion of glass particles inside the rotary scale dryer

Figure 2 shows an example of pictures captured among the many experimental sets, performed by placing spherical glass beads inside the rotary drum. Four flow patterns have been chosen to describe the initial startup at $\mathrm{t}=0 \mathrm{~s}$ as well as the evolution in mixed materials during a 17 -second period.

The flights are loaded in the bottom part of the drum. Once the flight rotation angle reaches a given level $(\approx$ $\pi / 2)$, the overloaded flight is discharged $(\mathrm{t}=3.5 \mathrm{~s}$ and $4.36 \mathrm{~s})$. When the flight is under-loaded $(t=17.24 \mathrm{~s})$, it exhibits areas where materials drop, while other parts allow for passage of the gas flow. A certain proportion of the aggregate remains at the bottom of the drum so as to form a granular bed.

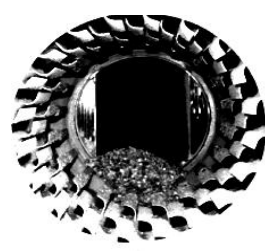

$\mathrm{t}=0 \mathrm{~s}$

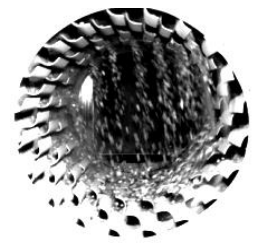

$\mathrm{t}=4.36 \mathrm{~s}$

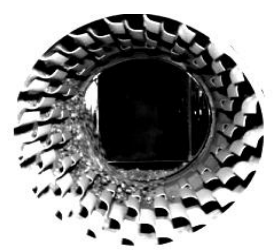

$\mathrm{t}=3.5 \mathrm{~s}$

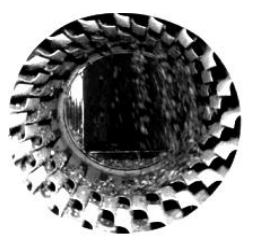

$t=17.24 \mathrm{~s}$
Fig. 3. Transversal motion of dry granular inside a rotary scale dryer.

A second campaign was carried out using aggregates with two distinct water contents: dry $\left(X_{s}=0 \%\right)$ and moist $\left(X_{s}=8 \%\right)$ aggregates with a mean diameter equal to $6 \mathrm{~mm}$ were introduced. The time series in Fig. 3 represents flow patterns associated with dry aggregate motion. The motions observed correspond quite well to findings from the experimental campaign conducted with spherical glass beads. From the recorded flow pattern, no variation in granular flow regime is detected across the various aggregate moisture fractions tested.

\subsection{Physical Assumptions}

\subsubsection{Cross Flow Description in a Rotary Drum}

Within the framework of building a relevant model, visualization at the pilot scale based on a range of experimental conditions leads to suggesting a two-part granular solid distribution. The majority of the granular flow pattern exhibits a dispersed phase in descending from the top of the drum, while the remaining part constitutes a granular bed at the bottom.

These observations are in good agreement with the classification of granular flow regimes inside a rotary drum according to the Froude number (Boateng 2008). In the present case, the granular flow regime in the drum is of the avalanche type (Ding 2002); such a regime gives rise to a homogenization of both the aggregate temperature and moisture in the crosssection, which in turn leads to defining $\mathrm{T}_{\mathrm{s}}(\mathrm{x}, \mathrm{t})$ (aggregate temperature at position $x$ along the drum axis at time $t$ ) and $\mathrm{X}_{\mathrm{s}}(\mathrm{x}, \mathrm{t})$ (aggregate water content at the same position and same time).

As indicated in the previous section for aggregate temperature and water content, each model variable or parameter is assumed to be uniform on any slice taken of the drum. It would therefore seem relevant to build a one-dimensional model that depends solely on time $t$ and position $x$ along the drum axis.

\subsubsection{Exchange Areas for Heat / Mass Transfer}

The aggregates are assumed to be spherical particles. The diagram in Fig. 4 summarizes the main exchange areas for heat and mass transfer during both drying and heating. The exchange areas between the gas and the drum environment, $S_{\mathrm{ge}}$, and between the granular bed and the environment, $S_{\mathrm{se}}$, depend on aggregate distribution within the cross-section.

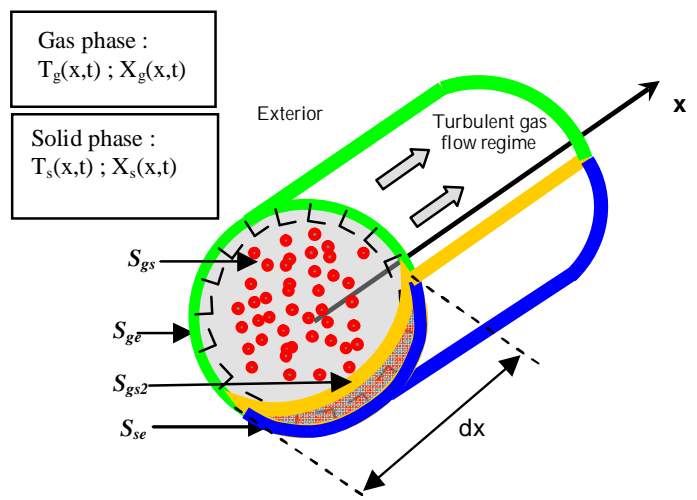

Fig. 4. Areas of exchange in a cross-section of the rotary drum in a slice

The $S_{\mathrm{gs}}$ exchange area, which is related to the transfer between gases and solids, depends on the particle and gas motions defined by their respective mean velocities, $\mathrm{V}_{\mathrm{s}}$ and $\mathrm{V}_{\mathrm{g}}$ (Fig. 5). As a rough approximation, it can be considered that $\mathrm{V}_{\mathrm{s}}<<\mathrm{V}_{\mathrm{g}}$ and that the relative velocity is negligible. The particle size ( $>2 \mathrm{~mm}$ ) leads to a 
particle Reynolds number $\left(\operatorname{Re}_{p}=\rho_{g a s} V_{s} d / \mu_{g a s}\right)$ much higher than the critical value of 1,000; hence, the flow regime is assumed to be Newtonian. The value of $S_{g s}$ takes into account the entire surface area of the sphere. The particle-particle interaction, emission and radiation of the gases have all been neglected, and the gas velocity is assumed to be the driving force for transfer phenomena in the dispersed phase, during which forced convection becomes the most important mechanism.

Since gas flow in the granular bed is much less than in the free part of the drum, no exchange between particles and gas in the granular bed needs to be taken in account. The heat transfer between gases and the granular bed is therefore restricted to the surface of the granular bed, $S_{g s 2}$. Moreover, this transfer depends on a characteristic length, $L$, which we have chosen as being the width of the granular bed surface.

\subsubsection{Definition of a Source Term for Evaporation}

The mass flow rate of water vapor between aggregates and hot air, $\dot{m}$, depends on both the temperature and moisture of the aggregates contributing to the heat and mass transfer coupling. This mass flow rate of water vapor also depends on the temperature of the solid particle; the induced mass transfer of water vapor can be evaluated by Fick's Law, as follows:

$$
\dot{m}=\left(k_{g s} \cdot S_{g s}+k_{g s 2} \cdot S_{g s 2}\right) \cdot\left(C_{s a t H_{2} O}-X_{g}\right)
$$

where $k_{g s}$ is the mass transfer coefficient for the dispersed phase, and $k_{g s 2}$ the mass transfer coefficient for the granular bed. The evaluation of these coefficients will be described in the next section. In addition, for both heat and mass transfer, water vapor is considered as a pure element and a perfect gas. The entire amount of water corresponding to the moisture content of an aggregate is assumed to lie on the surface of the solid particle (Fig. 5).

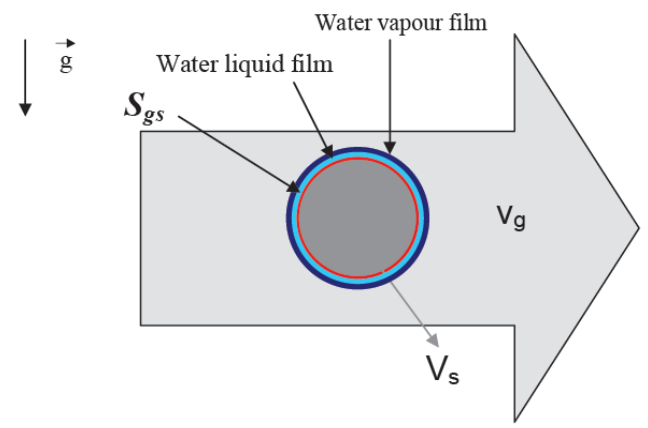

Fig. 5. Scheme representing the settling velocity and area of exchange at the solid scale in the gas flow disturbance

Water vapor saturation is thus anticipated around each solid particle. The saturation state is determined by the saturation pressure and depends on aggregate temperature, according to Clapeyron's formula, i.e.:

$\ln \frac{p_{\text {sat }}}{p_{0}}=\frac{M_{\mathrm{H}_{2} \mathrm{O}} \cdot L_{v}}{R} \cdot\left(\frac{1}{T_{0}}-\frac{1}{T_{s}}\right)$

This saturation implies a mass flow rate of water vapor around a particle for this particular saturation state. The mass flow rate of water vapor is calculated using the perfect gas law as:

$C_{\text {sath }_{2} \mathrm{O}}=\frac{n_{\text {sath }_{2} \mathrm{O}} \cdot M_{\mathrm{H}_{2} \mathrm{O}}}{\mathrm{Vol}}=\frac{p_{\text {sat }}}{R \cdot T_{s}} \cdot M_{\mathrm{H}_{2} \mathrm{O}}$

with $V o l$ equal to $1 \mathrm{~m}^{3}$.

\section{BUILDING AND DESCRIPTION OF THE 1D MODEL}

\subsection{Energy and Mass Balance in the Drum Cross-Section}

The basis of this model lies in a balance of energy and mass transfers between gases and aggregates. The five main unknowns of the model are: gas temperature $T_{g}(x, t)$, aggregate temperature $T_{s}(x, t)$, aggregate water content $X_{s}(x, t)$, gas water content $X_{g}(x, t)$, and transferred water mass rate $\dot{m}(x, t)$.

The energy balance yields two equations:

$$
\begin{aligned}
m_{s} \cdot C p_{s} \cdot \frac{\partial T_{s}}{\partial t}= & S_{g s} \cdot h_{g s} \cdot\left(T_{g}-T_{s}\right)+S_{g s 2} \cdot h_{g s_{2}} \cdot\left(T_{g}-T_{s}\right) \\
& -S_{s e} \cdot h_{s e} \cdot\left(T_{s}-T_{e x t}\right)-\dot{m} \cdot L_{v} \\
m_{g} \cdot C p_{g} \cdot \frac{\partial T_{g}}{\partial t} & =-S_{g s} \cdot h_{g s} \cdot\left(T_{g}-T_{s}\right)-S_{g s 2} \cdot h_{g s 2} \cdot\left(T_{g}-T_{s}\right) \\
& -S_{g e} \cdot h_{g e} \cdot\left(T_{g}-T_{e x t}\right)-\dot{m} \cdot C p_{v a p} \cdot\left(T_{g}-T_{s}\right)
\end{aligned}
$$

where $m_{s}$ and $m_{g}$ represent respectively the linear solid mass density and the linear gas mass density, while $C p_{s}$ and $C p_{g}$ denote respectively the specific heat capacity of solids and gases at constant pressure. $C p_{\text {vap }}$ is the specific heat capacity of water vapor at constant pressure, $L v$ the latent heat of vaporization for water, $h_{g s}$ the heat transfer coefficient between gas and solid, $h_{g s 2}$ the heat transfer coefficient between gas and the surface of the granular bed, $h_{s e}$ the heat transfer coefficient between the granular bed and the drum environment, and lastly $h_{g e}$ the heat transfer coefficient between gas and the drum environment. All these heat transfer coefficients will be defined in the following section.

The term on the left-hand side of Eq. 4 is the energy rate required to increase the temperature of aggregates with linear mass density $m_{s}$.

Several terms are redundant between Eqs. 4 and 5. HTS $\left(=S_{g s} \cdot h_{g s} \cdot\left(T_{g}-T_{s}\right)\right)$ is the heat transfer around solid particles. Since the particle is present within the gas flow, HTS is driven by convective heat transfer, which accounts for its form.

HTSB $\left(=S_{g s 2} \cdot h_{g s 2} \cdot\left(T_{g}-T_{s}\right)\right)$ is the heat transfer on the solid bed. HTSB results from convective heat transfer between the solid bed area and gases, which explains its form.

TLSB $\left(=S_{s e} \cdot h_{s e} \cdot\left(T_{s}-T_{s e}\right)\right)$ ) is the thermal loss around the solid bed. Since the temperature of solids differs from the outside temperature, thermal losses occur at this spot. This thermal loss consists of the conductive heat transfer through the drum wall, yet the transfer between wall drum and the outside is a mixed convective heat transfer. The equivalent heat transfer coefficient therefore depends on the coefficients of each heat transfer. 
TLG $\left(=S_{g e} \cdot h_{g e} \cdot\left(T_{g}-T_{e}\right)\right)$ is a thermal loss relative to gas. TLG corresponds to the convective heat transfer between the gas and the outside.

Water mass transfer gives rise to two equations for the solid and gaseous phases:

$$
\begin{gathered}
-\dot{m}=\frac{\partial X_{s}}{\partial t}+\frac{d X_{s}}{d x} \cdot V_{s} \\
\dot{m}=\frac{\partial X_{g}}{\partial t}+\frac{d X_{g}}{d x} \cdot V_{g}
\end{gathered}
$$

where $V_{s}$ and $V_{g}$ are respectively the solid velocity and the gas velocity.

The five main model unknowns can then be computed using the set of five Eqs. (1) and (4) through (7).

\subsection{Definition of Heat and Mass Transfer Coefficients}

$h_{g s}$ is derived from the Nusselt number, as calculated at the solid particle scale, i.e.:

$N u_{g s}=\frac{h_{g s} \cdot d}{\lambda_{g}}$

In this case, the Nusselt number is estimated from the Ranz-Marshall correlation, after particle drying (Boateng 2008):

$$
N u_{g s}=2+0.58 \cdot \operatorname{Re}^{0.5} \cdot \operatorname{Pr}^{0.33}
$$

On the other hand, $h_{g s 2}$ is derived from the Nusselt number at the granular bed scale, i.e.:

$$
N u_{g s 2}=\frac{h_{g s 2} \cdot L}{\lambda_{g}}
$$

The Nusselt number originates from a flat-plate correlation given that the transfer configuration lies on a flat plate (the solid bed area) (Schlichting 1960):

$$
N u_{g s 2}=0.023 \cdot \operatorname{Re}^{0.8} \cdot \operatorname{Pr}^{0.33}
$$

The granular bed is in contact with the rotary drum wall, while a thermal loss exists between the granular bed and the outside. $h_{s e}$ is quantified by means of the following relationship:

$$
\frac{1}{h_{s e}}=\frac{e}{\lambda_{w d}}+\frac{1}{h_{e x t}}
$$

where $h_{\text {ext }}$ is the heat transfer coefficient between the external wall of the rotary dryer and the outside. The rotary drum is in fact non-insulated, and the wall temperature, which equals $400^{\circ} \mathrm{K}$, remains constant along the drum. For $h_{g e}$, the reflection pattern is the same, except that $h_{g s}$ is taken into consideration when assessing $h_{g e}$ :

$\frac{1}{h_{g e}}=\frac{1}{h_{g s}}+\frac{e}{\lambda_{w d}}+\frac{1}{h_{e x t}}$

The evaporation energy is provided by the aggregates, while the energy for heating water vapor is provided by the gas (Messai 2007).

The aggregate distribution in a given cross-section implies two areas for mass transfer: one around the solid particle, the other on the granular bed surface. $k_{g s}$ is correlated with the Sherwood number, i.e.:

$S h_{g s}=\frac{k_{g s} \cdot d}{D}$

with $S h_{g s}$ obtained from the Ranz-Marshall correlation, after particle drying (Boateng 2008):

$S h_{g s}=2+0.58 \cdot \operatorname{Re}^{0.5} \cdot S c^{0.33}$

$k_{g s 2}$ is evaluated by:

$S h_{g s 2}=\frac{k_{g s} \cdot L}{D}$

Moreover, the mass transfer on the granular bed surface is characterized by the Sherwood number (Lee 2005):

$S h_{g s 2}=0.664 \cdot \operatorname{Re}^{0.5} \cdot S c^{0.33}$

\subsection{Final Version of the 1D Model}

In reality however, the drying step operates in a steady regime. This assumption supposes that the permutation from a temporal dimension to a spatial dimension is valid. Hence, the temperatures of solids and gases are solely dependent on the $x$-axis position.

Equations (4) and (5) are therefore modified into the following equations:

$$
\begin{aligned}
C p_{s} \cdot \frac{d T_{s}}{d x}= & \frac{1}{V_{s}} \cdot\left(\frac{S_{g s}}{m_{s}} \cdot h_{g s} \cdot\left(T_{g}-T_{s}\right)+\frac{S_{g s 2}}{m_{s}} \cdot h_{g s_{2}} \cdot\left(T_{g}-T_{s}\right)\right. \\
& \left.-\frac{S_{s e}}{m_{s}} \cdot h_{s e} \cdot\left(T_{s}-T_{e x t}\right)-\frac{\dot{m}}{m_{s}} \cdot L v\right) \\
C p_{g} \cdot \frac{d T_{g}}{d x}= & \frac{1}{V_{s}} \cdot\left(-\frac{S_{g s}}{m_{g}} \cdot h_{g s} \cdot\left(T_{g}-T_{s}\right)-\frac{S_{g s 2}}{m_{g}} \cdot h_{g s 2} \cdot\left(T_{g}-T_{s}\right)\right. \\
& \left.-\frac{S_{g e}}{m_{g}} \cdot h_{g e} \cdot\left(T_{g}-T_{e x t}\right)-\frac{\dot{m}}{m_{g}} \cdot C p_{v a p} \cdot\left(T_{g}-T_{s}\right)\right)
\end{aligned}
$$

with $\frac{S_{g s}}{m_{s}}$ and $\frac{S_{g s 2}}{m_{s}}$ referred to as linear specific areas. The water mass transfer expression then becomes:

$$
\begin{aligned}
& \frac{d X_{s}}{d x}=\frac{\dot{m}}{m_{s}} \cdot \frac{1}{V_{s}} \\
& \frac{d X_{g}}{d x}=\frac{\dot{m}}{m_{g}} \cdot \frac{1}{V_{g}}
\end{aligned}
$$

Lastly, the calculation of $\dot{m}$ is deduced from Equations (1) to (3) and summarized in the following equation:

$$
\dot{m}=\left(k_{g s} \cdot S_{g s}+k_{g s 2} \cdot S_{g s 2}\right) \cdot\left(\frac{p_{s a t}\left(T_{s}\right)}{R \cdot T_{s}} \cdot M_{H_{2} \mathrm{O}}-X_{g}\right)
$$

\section{MOdel TESTING}

\subsection{Sensitivity of the Calculation Step}

Physical resolution is achieved through use of a secondorder Runge-Kutta numerical method. 


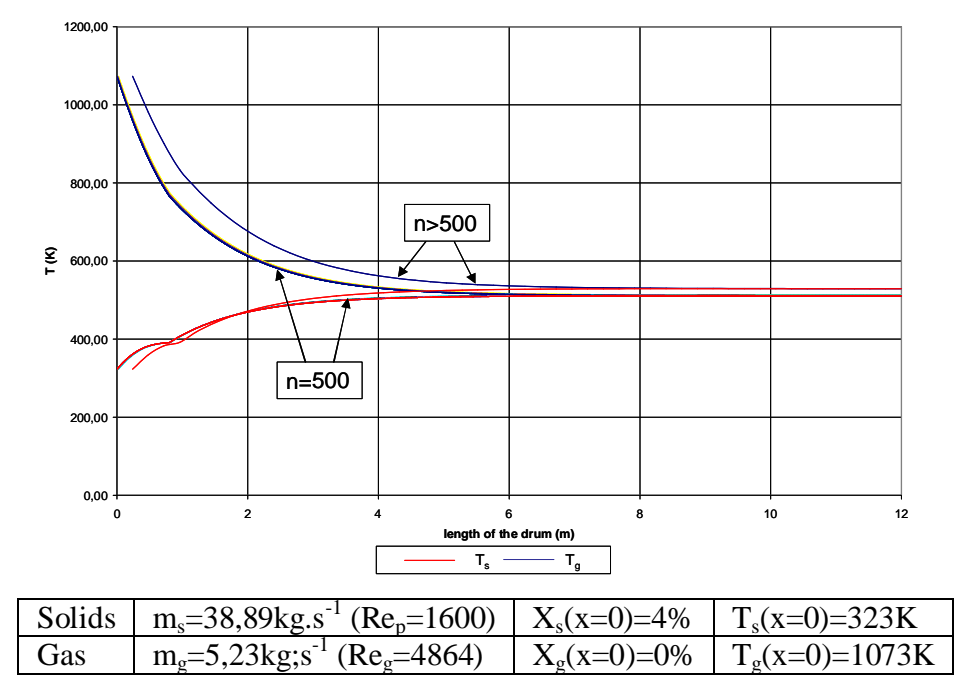

Fig. 6. Calculation step variation of numerical model

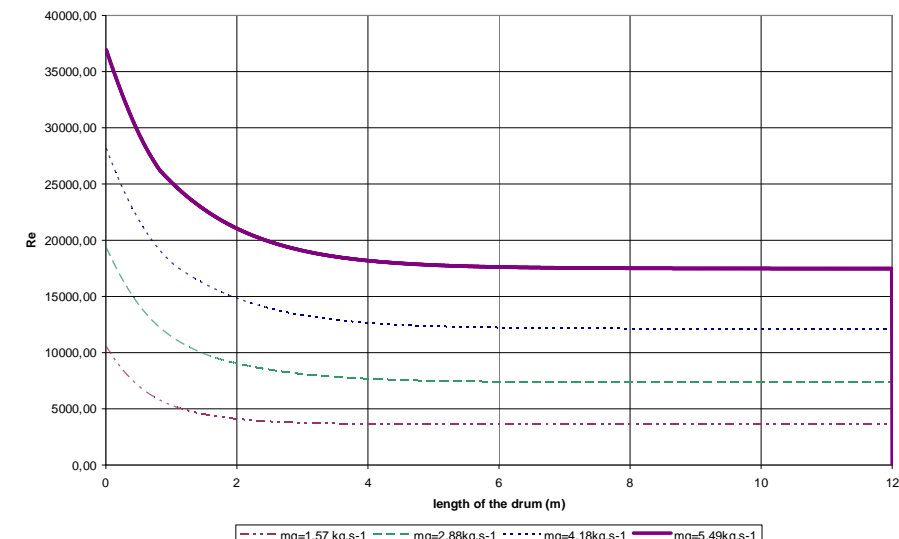

\begin{tabular}{|l|l|l|l|}
\hline Solids & $\mathrm{m}_{\mathrm{s}}=41,67 \mathrm{~kg} \cdot \mathrm{s}^{-1}\left(\mathrm{Re}_{\mathrm{p}}=1600\right)$ & $\left.\mathrm{X}_{\mathrm{s}} \mathrm{x}=0\right)=4 \%$ & $\mathrm{~T}_{\mathrm{s}}(\mathrm{x}=0)=323 \mathrm{~K}$ \\
\hline Gas & $\mathrm{m}_{\mathrm{g}}=1,57 \mathrm{~kg} \cdot \mathrm{s}^{-1}\left(\operatorname{Re}_{\mathrm{g}}=1468\right)$ & $\mathrm{X}_{\mathrm{g}}(\mathrm{x}=0)=0 \%$ & $\mathrm{~T}_{\mathrm{g}}(\mathrm{x}=0)=1073 \mathrm{~K}$ \\
& $\mathrm{~m}_{\mathrm{g}}=2,88 \mathrm{~kg} \cdot \mathrm{s}^{-1}\left(\operatorname{Re}_{\mathrm{g}}=2692\right)$ & & \\
& $\mathrm{m}_{\mathrm{g}}=4,18 \mathrm{~kg} \cdot \mathrm{s}^{-1}\left(\mathrm{Re}_{\mathrm{g}}=3916\right)$ & & \\
& $\mathrm{m}_{\mathrm{g}}=5,49 \mathrm{~kg} \cdot \mathrm{s}^{-1}\left(\operatorname{Re}_{\mathrm{g}}=5139\right)$ & & \\
\hline
\end{tabular}

Fig. 7. Reynolds number dependency along of the real drum

The number of calculation steps $n(n=L / \Delta x)$ ranges between 500 and 50,000 (where $\Delta x$ controls the accuracy of the set-up, i.e. $\Delta \mathrm{x}$ is the size of the $1 \mathrm{D}$ subdivision cells).

Figure 6 below displays the numerical results obtained. The initial conditions are explained in the figure caption, and the solid particle diameter equals $20 \mathrm{~mm}$. The Reynolds number for solid particles is 1,600, meaning that the Newtonian regime has been achieved.

Gas temperature decreases, whereas solid temperature increases along the main axis of the drum, which corresponds to the actual rotary dryer at the industrial plant (12 m long).

Both of these temperatures reach an identical value at the drum outlet. Some numerical assessments have demonstrated the independence of this phenomenon (in terms of both variations and final value) relative to the size $n$ of the numerical scheme, as long as $n$ exceeds 1,000 .

\subsection{Dependence of the dimensionless numbers on temperature}

As revealed by many of the authors presented in the introduction, granular transport exerts a strong impact on transfer phenomena (heat and mass). The Reynolds number for gases offers some information on both aggregate and air transport. The initial model conditions implemented are mentioned in the legend in Figure 7. The solid particle size here is $20 \mathrm{~mm}$, and the Reynolds number for solid particles equals 1,600 , which once again indicates that the Newtonian regime has been obtained. The Reynolds number is defined from the air velocity; this number also varies with the mass flow rate of the granular media. In turn, this flow rate induces a variation in the cross-section for gas flow passage. The corresponding results are presented in Fig. 7. 
Table 2 Initial conditions for the tests

\begin{tabular}{|c|c|c|c|c|c|c|c|c|}
\hline case & $\mathrm{m}_{\mathrm{s}}$ & $\mathrm{V}_{\mathrm{s}}$ & $\mathrm{S}_{\mathrm{gs}}$ & $\mathrm{S}_{\mathrm{gs} 2}$ & $\mathrm{~S}_{\mathrm{se}}$ & $\mathrm{X}_{\mathrm{s}(\mathrm{x}=0)}$ & $\mathrm{C}_{\mathrm{ps}}($ Hewitt 1997) & $\mathrm{d}$ \\
\hline 1 & 42,82 & 0,08 & 11,10 & $1,54.10^{-8}$ & 0,019 & 1,3 & 920 & 0,01 \\
\hline 2 & 41,53 & 0,08 & 10,74 & $1,52.10^{-8}$ & 0,019 & 1,3 & 920 & 0,01 \\
\hline 3 & 45,54 & 0,08 & 11,82 & $1,57.10_{-8}$ & 0,019 & 1,3 & 920 & 0,01 \\
\hline 4 & 44,38 & 0,08 & 11,52 & $1,56.10^{-8}$ & 0,019 & 1,3 & 920 & 0,01 \\
\hline
\end{tabular}

\begin{tabular}{|c|c|c|c|c|c|c|c|c|}
\hline case & $\mathrm{m}_{\mathrm{g}}$ & $\mathrm{V}_{\mathrm{g}}$ & $\mathrm{T}_{\mathrm{g}(\mathrm{x}=0)}$ & $\mathrm{S}_{\mathrm{ge}}$ & $\mathrm{C}_{\mathrm{pg}}$ & $\rho_{(\mathrm{T}=373)}($ Hewitt 1997) & $\mu_{(\mathrm{T}=373)}($ Hewitt 1997) & $\mathrm{T}_{\mathrm{ext}}$ \\
\hline 1 & 10,47 & 4,92 & 1032 & 0,124 & 1100 & 0,94 & $2,17.10^{-5}$ & 19,3 \\
\hline 2 & 10,47 & 4,92 & 1035 & 0,124 & 1100 & 0,94 & $2,17.10^{-5}$ & 13,2 \\
\hline 3 & 9,08 & 4,27 & 878 & 0,124 & 1100 & 0,94 & $2,17.10^{-5}$ & 21,3 \\
\hline 4 & 10,31 & 4,84 & 923 & 0,124 & 1100 & 0,04 & $2,17.10^{-5}$ & 9,9 \\
\hline
\end{tabular}

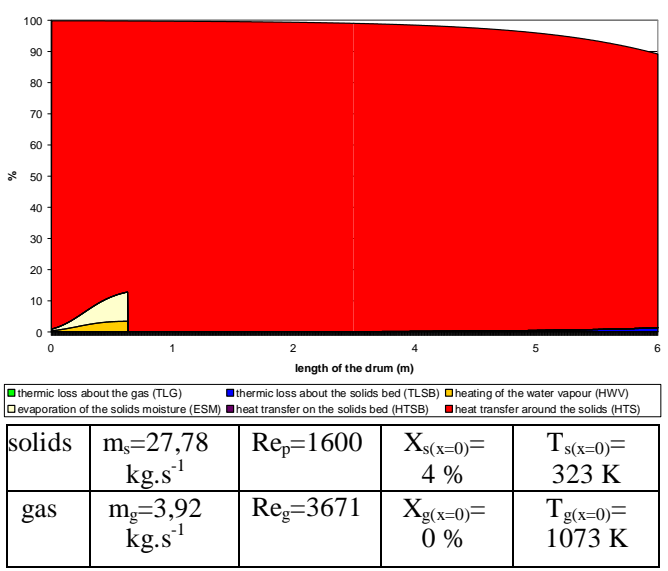

Fig. 8. Assessment of the energetic transfers

Given that the flow of air volume is highly dependent on $\mathrm{T}_{\mathrm{g}}$ and that air velocity is one of the parameters used to calculate the Reynolds number (when $\mathrm{T}_{\mathrm{g}}$ decreases), air velocity decreases, which causes the Reynolds number to drop as well. For a fixed value of $m_{s}$, as $\mathrm{m}_{\mathrm{g}}$ is increasing, the Reynolds number also rises.

The cross-section of the air passage remains fixed, hence air velocity rises as well. Since the other dimensionless numbers ( $\mathrm{Nu}, \mathrm{Sh}$ ) depend on the Reynolds number via the correlations previously exposed, these other numbers decrease to the same extent, as observed through the Reynolds number with an increasing abscissa. Moreover, the temperature difference between gases and solids decreases, meaning that the transfer amount is smaller in order to obtain a similar temperature for solids and gases.

\subsection{Energy transfer evaluation}

An assessment of the relative weight of each term in Eqs. (4) and (5) is now proposed so as to compare each transfer and validate assumptions along the drum. The initial conditions are presented in Table 2 with a calculation step equal to 2,000 .

Figure 8 displays the distribution of energy transfer, for the purpose of evaluating the evolution in each energy transfer along half the drum length. These initial conditions have been included on the legend in Fig. 8.

The primary energy transfer is correlated with water evaporation and water vapor heating at the drum inlet. This transfer occurs along the first $50 \mathrm{~cm}$.
The vapor flow rate is in fact the difference in vapor mass concentration between gases and solids. Nevertheless, the vapor mass concentration on solids is tied to saturation temperature. The vapor flow rate is therefore independent of the moisture content found on the solids.

The mass transfer however is switched off when moisture content of the solids equals zero, which explains the sudden interruption of transfer. These energy transfers represent the drying step for aggregates. It can be observed up until the outlet that the main energy transfer pertains to aggregate heating.
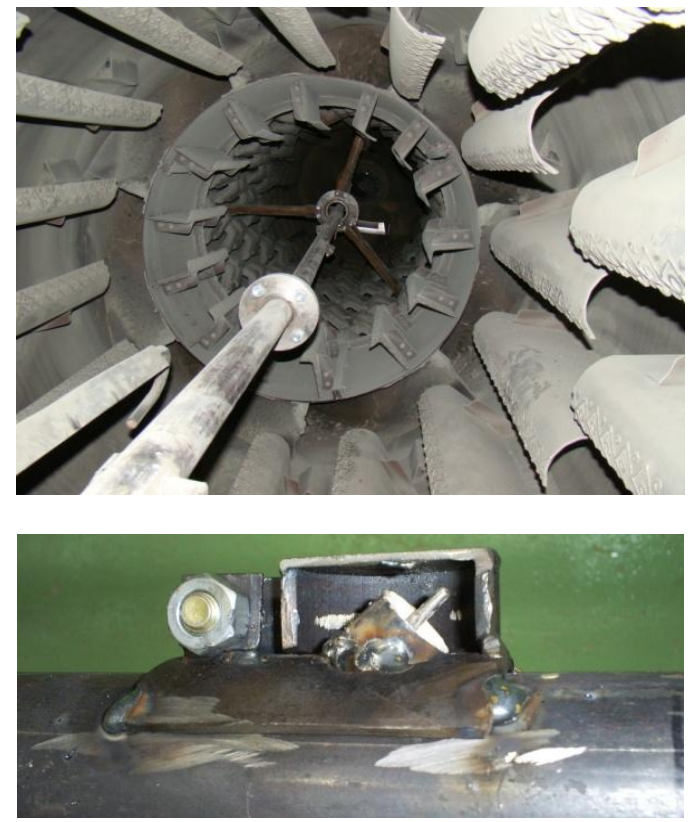

Fig. 9. probes support in the rotary drum and probe

\section{MODELING VS. EXPERIMENTATION AT THE INDUSTRIAL SCALE}

An industrial mix-asphalt processing unit has been monitored. Eight temperature probe supports were implemented in the longitudinal axis along a drum (12 meters long), in order to measure gas temperature. Figure 9 shows these probe supports within the drum. The probes are protected against granular flow by means of a steel semi-shell; they were insulated from the support in order to avoid heat transfer conduction 


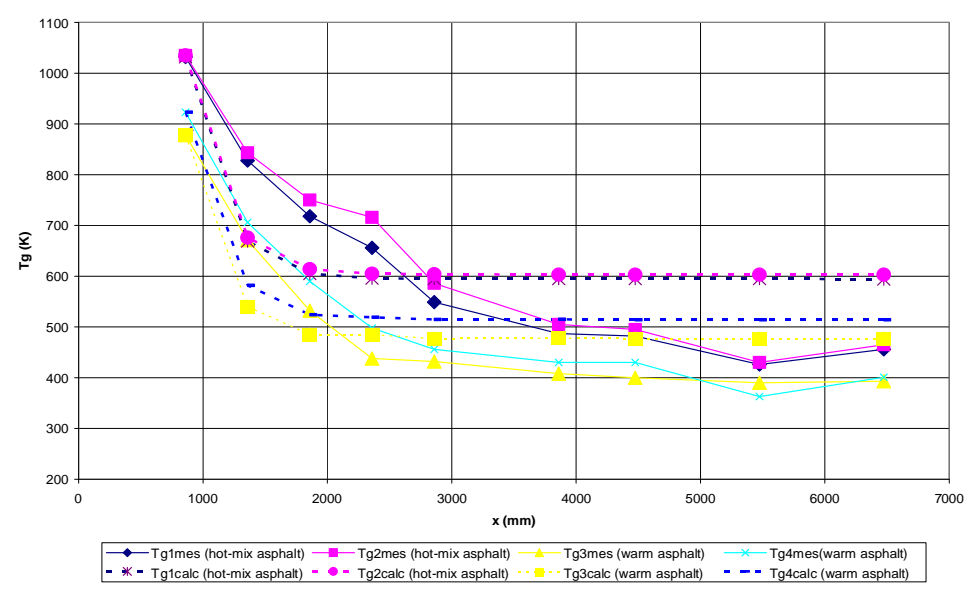

Fig. 10. Comparison between measured and calculated gases temperature

for the support and hence temperature measurement deviation. K-thermocouples were chosen due to a temperature range varying between $400^{\circ} \mathrm{K}$ and $1500^{\circ} \mathrm{K}$. The actual process was monitored at the same time so as to record the parameters required by the model, including: solid feed rate and initial moisture content, gas temperature, and mix-asphalt temperature.These recorded parameters are necessary to implement the model in a way that compares calculated output with measurement results. The four application cases studied are detailed in Table 2.

The various tests conducted account for several productions using different techniques. The classical hot-mix asphalt and the warm-asphalt technique differ in terms of asphalt concrete temperature at the plant outlet.

The gas temperatures for these four cases have been compared at the same location as for the probes. Figure 10 presents a comparison between measured and calculated temperatures.

The trends are identical between the measured and calculated values: the mean deviation is approximately $17 \%$ over the entire dataset, and the maximum deviation equals $41 \%$.

A better estimation of both the transfer coefficients and exchange areas could improve the model. For the time being however, the transfer coefficients are being estimated from the standard correlation.

The local influence of a granular flow composed of several material classes on the gas phase is essential to a good evaluation of the momentum transfer. A similar study is necessary of the exchange area, through improving the pilot-scale measurements.

\section{Conclusion}

Experimental measurements at both the pilot scale (1/3) and industrial scale (full-scale) of a co-current rotary drum have been performed in order to build a drying and heating model applicable to mix-asphalt processes. The first experimental stage was conducted using different materials (glass spheres, then moist and dry aggregates) without any flow gases to allow characterizing the granular flow regime. This visualization tool proved relevant to the construction of a physical model based on two transfer areas. One of these areas contained a dispersed phase, while the second was a granular bed located in the bottom part of the drum. From this physical consideration, a 1D model was developed using the energy and mass balance equation, along with a suitable coupling between heat and mass transfer at the aggregate scale. The system of equations was solved for various initial conditions and demonstrated applicability beyond 1,000 iterations. The strong dependence of the Reynolds number on the temperature gradient in the flow direction ( $x$-axis) reveals that both the exchange area and transfer coefficients for heat and mass transfers must be taken into account and validated in order to proceed with the next step of this research. Measurements using infrared tomography at the drum shell are currently underway. The second work step has consisted of measuring gas temperatures in an industrial rotary drum. The model was validated with respect to gas temperature values, since a suitable evolution was obtained with the two approaches for different techniques (hot- and warmasphalt techniques). Nevertheless, a complete validation still needs to be performed on the entire set of parameters.

\section{ACKNOWLEDGEMENTS}

The authors would like to express their thanks to Ermont-Fayat Group for the pilot scale device lending. The authors are grateful to the SEMR / CETE Normandie-Centre department for the monitoring of the industrial mix-asphalt processing unit.

\section{REFERENCES}

Boateng, A.A. (2008). Rotary kilns Transport phenomena and Transport processes, ButterworthHeinemann.

Bertrand, F., L.-A. Leclaire and G. Levecque (2005). DEM-based models for the mixing of granular materials. Chemical Engineering Science, 60(8-9), 2517-2531.

Chaudhuri, B., F.J.Muzzio and M.S. Tomassone (2006). Modelling of heat transfer in granular flow in rotating vessels. Chemical Engineering Science, 61(19), 6348-6360. 
Chen, X. and M. Louge (2008). Heat transfer enhancement in dense suspensions of agitated solids. Part I: Theory. International Journal of Heat and Mass Transfer 51(21-22), 5108-5118.

Ding, Y.L., R.N. Forster, J.P.K. Seville and D.J. Parker (2002). Granular motion in rotating drums bed turnover time and slumping-rolling transition. Powder Technology 124(1-2), 18-27.

Henein, H., J.K. Brimacombe and A.P. Watkinson (1983). Experimental study of transverse bed motion in rotary kilns. Metallurgical Transactions B: Process Metallurgy 14(2), 191-205.

Huang, Q., H. Zhang and J. Zhu (2009). Experimental study on fluidization of fine powders in rotating drums with various wall friction and baffled rotating drums. Chemical Engineering Science, 64(9), 2234-2244.

Hewitt, G.F., G.H. Shires and Y.V. Polezhaev (1997). International Encyclopedia of Heat and Mass Transfer, Boca Raton, FL: CRC Press.

Heydenrich, M.D., P. Greeff, A.B.M. Heesink and G.F. Versteeg (2002). Mass transfer in rolling rotary kilns: a novel approach. Chemical Engineering Science 57(18), 3851-3859.

Iguaz, A., A. Esnoz, G. Martinez, A. Lopez and P. Vrseda (2003). Mathematical modelling and simulation for the drying process of vegetable wholesale by-products in a rotary dryer. Journal of Food Engineering 59(2-3), 151-160.

Krisjantdottr, O., S.T. Muench, L. Michael and G. Burke (2007). Assessing potential for warm-mix asphalt technology adoption. Transportation Research Record 2040, 91-99.

Lee, C.S., F. Hagigat and W.S. Ghaly (2005). A study on VOC source and sink behaviour in porous building - analytical model development and assessment. Indoor Air 15, 183-196.

Lisboa, M.H., D.S. Vitorino, W.B. Delaiba, J.R.D. Finzer and M.A.S. Barrozo (2007). A study of particle motion in rotary dryer. Brazilian Journal of Chemical Engineering 24(3), 365-374.

Mellmann, J. (2001). The transverse motion of solids in rotating cylinders - forms of motion and transition behavior. Powder Technology 118(3), 251-270.

Messai, S., J. Sghaier, D. Lecomte and A. Belghith (2007, august). Etude expérimentale du séchage convectif à haute température d'un milieu granulaire. 13èmes Journées Internationales de Thermique.

Mujumdar, A.S. (2007).An overview of innovation in industrial drying: current status and R\&D needs. Transport Porous Media 66(1-2), 3-18.
Ristow, G.H. (1998). Flow properties of granular materials in $3 D$ geometries. $\mathrm{Ph} \mathrm{D}$. Thesis, PhilipsUniversitat Marburg, Marburg, Germany.

Romier, A., M. Audeon, J. David, Y. Martineau and F. Olard (2006). Low-Energy Asphalt with performance of hot-mix asphalt. Journal of Transportation Research Board 1962, 101-112.

Sclichting, H. (1960). Boundary layer theory, $4^{\text {th }}$ ed. McGrawhill, New York.

Sheehan, M.E., P.F. Britton and P.A. Schneider(2005). A model for solids transport in flighted rotary dryers based on physical considerations. Chemical Engineering Science 60(15), 4171-4182.

U.S. Environmental Protection Agency (2004). Emissions factor documentation for AP-42. Hot mix asphalt plant. Final report. Report from USEPA office or Air Quality Planning and Standards. Emissions Measurement Center.

Zhu, K., C.K. Wong, S.M. Rao and C.H. Wang (2004). Pneumatic conveying of granular solids in horizontal and inclined pipes. American Institute of Chemical Engineers Journal 50(8), 1729-1745. 